\section{Online forward triage during the COVID-19 outbreak}

\author{
Wolf E Hautz 지, Aristomenis Exadaktylos, Thomas C Sauter
}

\begin{abstract}
Health systems face major challenges during the COVID-19 pandemic with new information and challenges emerging daily and frequently changing guidelines. Online forward triage tools (OFTTs) provide useful information, direct patients and free physician resources. We implemented an OFTT targeted at the current pandemic, adapted the content and goals and assessed its effects. The OFTT was implemented on 2 March 2020 and modified regularly based on the revised testing criteria issued by the Swiss Federal Office of Public Health. After testing criteria liberalised, a chatbot tool was set up on 9 April 2020 to assess urgency of testing, referral to available testing sites and need for emergency care. In the first 40 days of the OFTT, there were more than 17300 visitors and $69.8 \%$ indicated they would have contacted the healthcare system if the online test had not been available. During the initial week of operation, using the conservative testing strategy, $9.1 \%$ of visitors received recommendations to be tested, which increased to $36.0 \%$ of visitors after a change in testing criteria on 9 March 2020. Overall, since the implementation of the tool, $26.27 \%$ of all users of the site have been directed to obtain testing. The Chatbot tool has had approximately 50 consults/day.

Setting up an OFTT should be considered as part of local strategies to cope with the COVID-19 pandemic. It may ease the burden on the healthcare system, reassure patients and inform authorities. To account for the dynamic development of the pandemic, frequent adaptation of the tool is of great importance. Further research on clinical outcomes of OFTT is urgently needed.
\end{abstract}

\section{INTRODUCTION}

Health systems worldwide face major challenges due to the current COVID-19 pandemic. In addition to identifying the rapidly increasing number of infected people and caring for the sick, the system needs to attend to anxious and potentially misinformed citizens. New information

Department of Emergency Medicine, Inselspital University Hospital Bern, Bern, Switzerland

Correspondence to Dr Thomas C Sauter, Department of Emergency Medicine, Inselspital University Hospital Bern, 3010 Bern, Switzerland; Thomas.Sauter@insel.ch

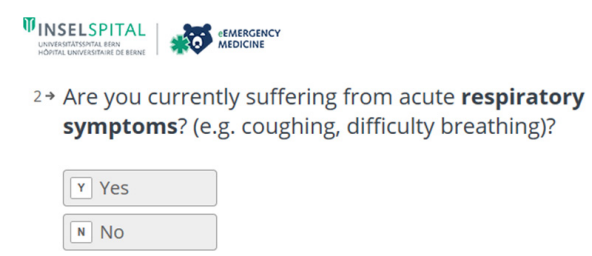

Figure 1 Screenshot of the online forward triage tool.

about the disease emerges daily. As a result of this, and changes in the testing capacity of health services, guidelines have been adjusted frequently during the pandemic. It is difficult, therefore, for physicians and patients to maintain currency with respect to these changing guidelines. Thus an online forward triage tool (OFTT) may provide a current, credible and practical source of information for patients and physicians, direct patients to the correct level of care and free physician resources for sicker patients. ${ }^{1}$ The requirements for such an OFTT in terms of timeliness and flexibility in adapting to changing guidelines are high and represent a major challenge in operating such an instrument.

It is estimated that around a third of adults use online tools to assess their health, ${ }^{2}$ but this figure may be higher during a pandemic. During the H1N1 pandemic, an OFTT prevented an estimated 100000 emergency department visits in the USA. ${ }^{34}$ The objectives of using an OFTT (eg, prevention of emergency visits, management of testing capacities) can vary during the course of a pandemic and may need to be adapted from recommendations for testing, to urgency of testing, available testing facilities and referral to emergency services to ensure safe patient care.

\section{METHOD}

We developed and maintain an OFFT as a new non-commercial initiative based on the official testing guidelines published by the Swiss Federal Office of Public Health (figure 1). During the first months of the pandemic, the test recommendation in Switzerland was based on known contact with a patient with COVID-19 and history of travel to affected areas (Italy). During the course of the pandemic, the recommendation changed to a risk group based testing strategy (testing in healthcare professionals, patients $>65$ years and patients with pre-existing conditions such as hypertension). These test recommendations of the Federal Office for Public Health (FOPH) were immediately implemented in our tool. With increasing spread of the virus and increases in testing capacities, testing criteria in Switzerland, issued by the FOPH on a national level, changed to a very liberal testing regime (now providing free testing for everyone with even the slightest symptoms or minimal contacts to confirmed cases). This limited our initial approach to provide a recommendation regarding the indication for testing.

We responded to this change in conditions by implementing a technically more advanced successor to our primary tool in cooperation with several national and international partners. ${ }^{5}$ The advanced application employs chatbot technology ${ }^{5}$ that adapts its questions to previous answers by the same patient. The focus of this further development of our first tool was placed on recommendations regarding the urgency of consultation, possible places for such consultation and the need for self-isolation rather than whether to test or not. This application is subject to the European Regulations for medical products.

Importantly, those users who are advised to obtain a test are instructed to call their provider beforehand, reducing the risk of exposure for providers and other patients in their facilities.

Data collected are described by date and testing recommendation given. No patients were involved in the design and conduct of this study. We plan to disseminate the findings of this study among patients in scientific presentations to the public at the University of Bern. Both tools are provided free of charge and the authors have no commercial interest in the products.

\section{RESULTS}

During the first 40 days of the initial OFTT, the site saw more than 17300 visitors-69.8\% indicated they would have contacted the healthcare system if the online test had not been available. As of 13 April 2020, 72 different websites run by physicians or dentists in private practice referred to our OFFT. Recommendations regarding testing varied greatly over time (figure 2). 


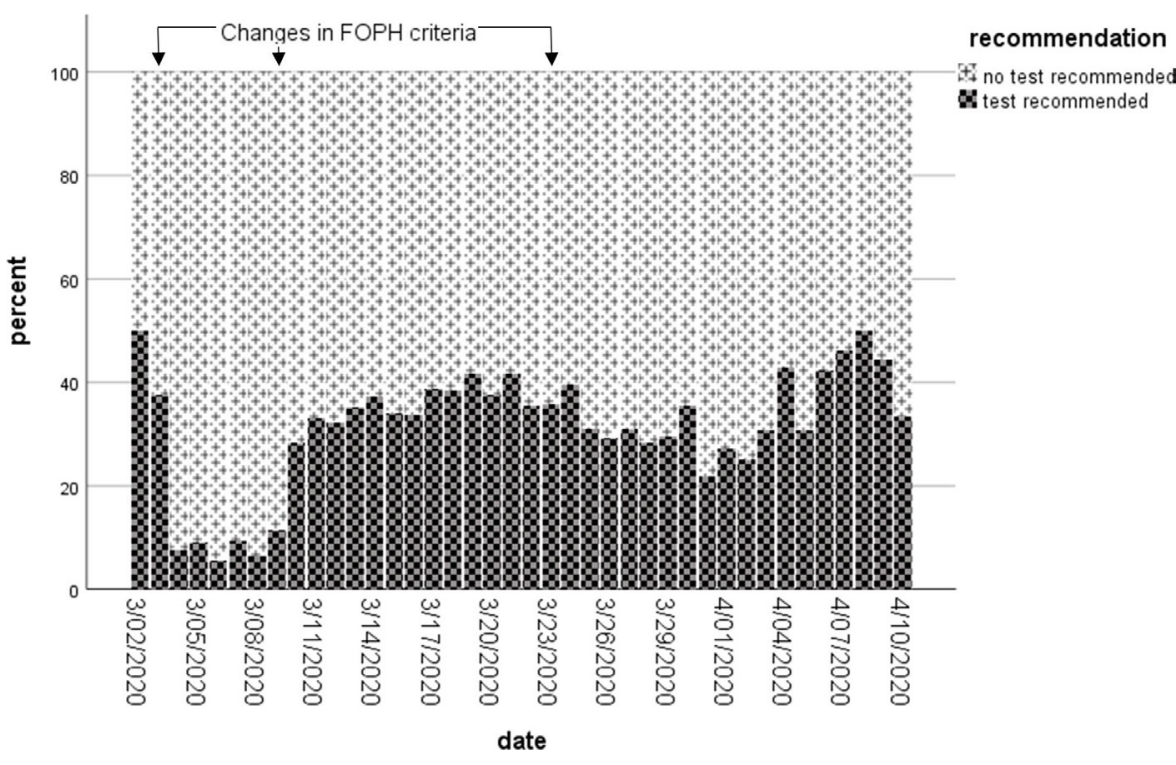

Figure 2 Recommendation by date of inquiry. FOPH, Federal Office for Public Health.

In the initial week of operation, $9.07 \%$ of those visiting the site were recommended to have a test. A major change in FOPH testing criteria on 9 March 2020, and adaptation of the OFTT, led to an increase in recommendations of all users to get tested to $35.97 \%$. A subsequent change on 22 March had a negligible effect. The proportion of visitors who were recommended to have tests differed between regions. This difference could be an indication of the prevalence of COVID-19 in different regions. Overall, $26.27 \%$ of all users of the site were directed to obtain a test for novel coronavirus.

The Chatbot application, which focuses on time and place of treatment, has had an average of 50 full assessments/day.

\section{DISCUSSION}

In the initial phase of the pandemic, the vast majority of our OFTTs' users did not fulfil the national Swiss testing criteria in effect at the time of their inquiry. For a large number of users, the risk of infection from unnecessary travel and exposure to potentially ill patients at testing sites may have been avoided and the healthcare system relieved of unnecessary consultations. The very high acceptance among general practitioners and dentists as indicated by the large number of patients referred to the OFTT underlines the professionals' need for advice. On a macro level, analysis of user responses can identify what changes in FOPH testing criteria are responsible for what change in recommendations and support authorities in balancing testing criteria and capacity. Analyses of user location may further inform dynamic regional allocation of testing capacities, help target interventions for education and information and localise hot spots of COVID-19.

Adapting a tool not only to current test criteria, but also to current problems society and the healthcare system are facing and that might change during a pandemic is a major challenge for the operation of OFTTs. Depending on the current state of the pandemic, the aim of an OFTT may be to manage testing capacity or to protect a healthcare system from collapsing due to too many emergency consultations that could be managed elsewhere. However, it is essential to adapt these strategies and consequently to adapt or even shut down an OFTT if there is sufficient testing capacity or if it becomes apparent that indicated emergency visits are not taking place, for example, because of fear of infection.

Further research should be carried out to improve the accessibility of OFTTs for all populations and age groups. A first work on a self-triage tool for COVID-19 could confirm a good usability in patients, recruited from an academic setting. ${ }^{6}$ In Iran, during the COVID-19 pandemic, an on-line screening system results in specific advice sent to the user by SMS, including referral to the appropriate health centre.

In addition to OFTT, other telehealth services such as video consultations may improve these online services. ${ }^{8}$

\section{LIMITATIONS TO CONSIDER}

Implementing an OFTT is technically easy ${ }^{9}$ but requires careful consideration of applicable data privacy legislation. Because of this legislation, no information is available on the course of the disease in the individual users studied and on socioeconomic factors influencing the use of the OFTT. These privacy issues may be one reason why, despite the increasing use of digital decision support tools in general, research investigating patient outcomes is lacking. Further research on outcomes, in particular on the accuracy of recommendations and on the adherence to these recommendations is important. Factors that influence the acceptance and use of such tools should further be investigated.

\section{CONCLUSION}

Setting up and promoting an OFTT is straightforward and should be considered as part of local strategies to cope with the COVID-19 pandemic. It may ease the burden on the healthcare system, reassure patients and inform authorities. To account for the dynamic development of the pandemic, frequent adaptation of the tool not only to changing guidelines, but also to changing requirements of a tool during a pandemic is of great importance.

Contributors All authors designed the study and manuscript, accepted the final version and are responsible for all aspects.

Funding The present work is supported by the Swiss National Foundation within the the Special Call on Coronaviruses (196615). The Swiss National Science Foundation has no influence on the content of the research or on the decision to publish it.

Competing interests None declared.

Patient consent for publication Not required.

Ethics approval The relevant ethics committee waived the need for full ethical review (Req-202000289).

Provenance and peer review Not commissioned; externally peer reviewed.

\section{0 OPEN ACCESS}

Open access This is an open access article distributed in accordance with the Creative Commons Attribution Non Commercial (CC BY-NC 4.0) license, which permits others to distribute, remix, adapt, build upon this work non-commercially, and license their derivative works on different terms, provided the original work is properly cited, appropriate credit is given, any changes made indicated, and the use is non-commercial. See: http:// creativecommons.org/licenses/by-nc/4.0/

(C) Author(s) (or their employer(s)) 2021. Re-use permitted under CC BY-NC. No commercial re-use. See rights and permissions. Published by BMJ.

Handling editor Simon Carley

\section{Check for updates}

To cite Hautz WE, Exadaktylos A, Sauter TC. Emerg Med J 2021;38:106-108.

Received 16 April 2020

Revised 7 November 2020 


\section{Report from the front}

Accepted 11 November 2020

Published Online First 11 December 2020

Emerg Med J 2021;38:106-108.

doi:10.1136/emermed-2020-209792

\section{ORCID iDs}

Wolf E Hautz http://orcid.org/0000-0002-2445-984X

Thomas C Sauter http://orcid.org/0000-0002-6646-

5789

\section{REFERENCES}

1 Hollander JE, Carr BG. Virtually perfect? telemedicine for Covid-19. N Engl J Med 2020;382:1679-81.
2 Millenson ML, Baldwin JL, Zipperer L, et al. Beyond Dr. Google: the evidence on consumer-facing digital tools for diagnosis. Diagnosis 2018;5:95-105.

3 Spaulding AB, Radi D, Macleod H, et al. Design and implementation of a statewide influenza nurse triage line in response to pandemic H1N1 influenza. Public Health Rep 2012;127:532-40.

4 Kellermann AL, Isakov AP, Parker R, et al. WebBased self-triage of influenza-like illness during the 2009 H1N1 influenza pandemic. Ann Emerg Med 2010;56:288-94.

5 In4Medicine AG. COVID-GUIDE. together against coronavirus, 2020. Available: https://covidguide. health
6 Schrager JD, Schuler K, Isakov AP, et al. Development and usability testing of a web-based COVID-19 Selftriage platform. West J Emerg Med 2020;21:1054--8.

7 Amir-Behghadami M, Janati A. Iranian national COVID-19 electronic screening system: experience to share. Emerg Med J 2020;37:412-3.

8 Judson TJ, Odisho AY, Neinstein AB, et al. Rapid design and implementation of an integrated patient self-triage and self-scheduling tool for COVID-19. J Am Med Inform Assoc 2020;27:860-6.

9 Sauter TC, Hautz WE. how_to: web-based forward triage for COVID-19. Available: https://www.enotfallmedizin. ch/how_to_web-based_forward_triage_during_the_ covid_19_outbreak/ 